\title{
A RETROSPECTIVE STUDY ON BLUNT INJURY ABDOMEN
}

\author{
Kopperundevi Vadamalai', Jagadeesan Subramani2, Kiruthiga Sankaranarayanan ${ }^{3}$
}

${ }^{1}$ Associate Professor, Department of General Surgery, Thanjavur Medical College and Hospital.

${ }^{2}$ Assistant Professor, Department of General Surgery, Thanjavur Medical College and Hospital.

3 Post Graduate, Department of General Surgery, Thanjavur Medical College and Hospital.

\section{ABSTRACT}

Blunt injury abdomen is the leading cause of morbidity and mortality in all age groups. Blunt trauma differs from penetrating trauma as different organs are characteristically injured by compression from blunt straining. A total of 53 cases of blunt trauma were studied in this study for the period of 1 year. In this study, commonest cause for blunt abdominal trauma was road traffic accident. The maximum incidence was noted in 20-40 middle age group of which $90 \%$ male patients were injured. The outstanding features of injury to solid organs are haemorrhage and shock, which in hollow visceral injury shock follows with the development of peritonitis. The aim of this study is to analyse the pattern of visceral injuries and find out the morbidity and mortality in blunt abdominal trauma. X-ray revealed $100 \%$ advantage in hollow viscus perforation in blunt trauma in this study. Common mode of treatment opted was surgery. Wound infection was the common complication after surgery for blunt trauma patients. Septicaemia was the common cause of death in this study.

\section{AIM OF THE STUDY}

- To evaluate the age and sex incidence of the involved patient population.

- To evaluate the different organ systems involved and various modes of presentations as a primary tool in early diagnosis.

- To find a possible treatment protocol cases of blunt trauma to the abdomen following road traffic accident.

\section{KEYWORDS}

Blunt Abdominal Trauma, Abdominal Organs, Road Traffic Accidents, Operative Management.

HOW TO CITE THIS ARTICLE: Vadamalai K, Subramani J, Sankaranarayanan K. A retrospective study on blunt injury abdomen. J. Evolution Med. Dent. Sci. 2016;5(25):1336-1338, DOI: 10.14260/jemds/2016/314

\section{INTRODUCTION}

Blunt trauma is one of the leading preventable causes of unnatural death in developed and developing countries. The incidence of abdominal trauma makes trauma as one of the leading causes of acute abdomen in a day-to-day surgical practice. ${ }^{1}$ Rapid resuscitation is necessary to save the unstable patients. Blunt trauma is particularly deceptive, as the clinical manifestation may be delayed for hours or days, even though internal damage is serious and sometimes lethal.

In open cases of abdominal trauma, the clinical manifestations, diagnosis and management will be easier, but closed cases of abdominal trauma offers a great challenge to the treating surgeon. Diagnosis and decision of surgery depends mainly on careful and repeated clinical examination with basic investigations. Systemic approach to preoperative diagnosis and preparation, intraoperative inspection, decision, postoperative care and observation for complications is essential for successful management of individual cases. This study is based on solid organ injury and hollow viscus perforation, its diagnosis and management were briefly discussed.

\section{METHODS}

This study was carried out on patients with blunt trauma from January 2015 to December 2015. Cases were selected with history of trauma to abdomen.

Financial or Other, Competing Interest: None.

Submission 08-02-2016, Peer Review 26-02-2016,

Acceptance 29-02-2016, Published 28-03-2016.

Corresponding Author:

Dr. Kopperundevi Vadamalai,

T1, Vadivu Abodes, Rahuman Nagar,

Medical College Road,

Thanjavur-4.

E-mail:drvkdevi@gmail.com

DOI: $10.14260 /$ jemds $/ 2016 / 314$
Based on careful history and meticulous physical examination combined with adjunctive investigations, a decision to operate or to manage conservatively was taken. Total of 53 patients were taken for this study.

\section{Inclusion Criteria}

All patients who had history of blunt injury abdomen due to road traffic accidents, assault, accidental fall were included.

Patient who have been managed conservatively were excluded and associated orthopaedic injuries, severe head injuries, chest injuries were excluded.

For all patients thorough history was taken along with thorough physical and general examinations. Patient was operated on emergency basis or wait and watch policy. For patients undergoing conservative management, nasogastric tube aspiration, pulse rate blood pressure monitoring, urine output measurement done. Analgesics and antibiotics were given and the patient was put on observation. In case of death, cause of death noted.

\section{RESULTS}

There were total of 53 cases admitted in our hospital as blunt injury abdomen, 48 patients were male and 5 patients were female. All the cases were managed surgically. Out of 53 cases 26 patients had hollow viscus perforation, 27 patients had solid organ injuries were treated surgically.

\section{DISCUSSION}

Blunt abdominal trauma is the leading cause of morbidity and mortality in all age groups. Solid organs (e.g. liver and spleen) are more readily lacerated by blows than hollow organs such as empty stomach, intestine, urinary bladder. FAST. $(2,3,4,5)$ was major advantage for unstable patients. In recent years, FAST (Focussed Abdominal Sonography for Trauma) has emerged as a useful diagnostic test. In most cases, FAST may be 
completed within 3 to 4 minutes. $(6,7,8,9,10)$ The cause of death in injury of parenchymatous viscera like liver, spleen, kidneys is haemorrhage into abdominal cavity. There was predominance of middle aged men. There were total of 53 cases admitted in our hospital as blunt injury abdomen, 48 patients were male and 5 patients were female. 11

In all our cases abdominal pain was the most common symptom, while abdominal distension was the second most common symptom followed by vomiting and haematuria.

Out of 53 cases, $80 \%$ had diffuse abdominal tenderness at the time of admission. There was local and generalised guarding present; 11 patients had shock out of which 5 patients had splenic injury, 3 had liver injury, 2 had small bowel perforation and 1 had large bowel perforation. Bowel sounds were absent in $65 \%$ cases.

In present study, maximum number of patients $60 \%$ were brought to the hospital within 5-10 hours after injury.

In this study, all 53 cases were managed surgically. Only 8 cases could be operated within 3 hours after admission, while $60 \%$ were operated within 4-6 hours of admission.

The duration of Hospital stay varied from 7-24 days, out of which 9 patients expired.

The most frequently injured organ in blunt injury abdomen are hollow viscus organs (45\%-55\%), spleen (30\%), liver (10\%).

In the hollow viscus injury, the small bowel injury followed by mesenteric injury. Urinary bladder injury. ${ }^{12,13}$ (N Modi, Tonge et al.) was found in $5 \%$ of cases.

\section{Management}

All 53 cases were managed surgically.

\section{Postoperative Complications}

In present study, wound infection. ${ }^{14}$ was the most common complication noted followed by pneumonia, pelvic abscess.

\section{Mortality}

In this present study, out of 53 cases 9 patients ended in mortality. Septicaemia was the most common cause of death. Hypovolemic shock was the cause of death in 1 case and ARDS in another case.

\section{Causes of Death in Blunt Trauma Abdomen}

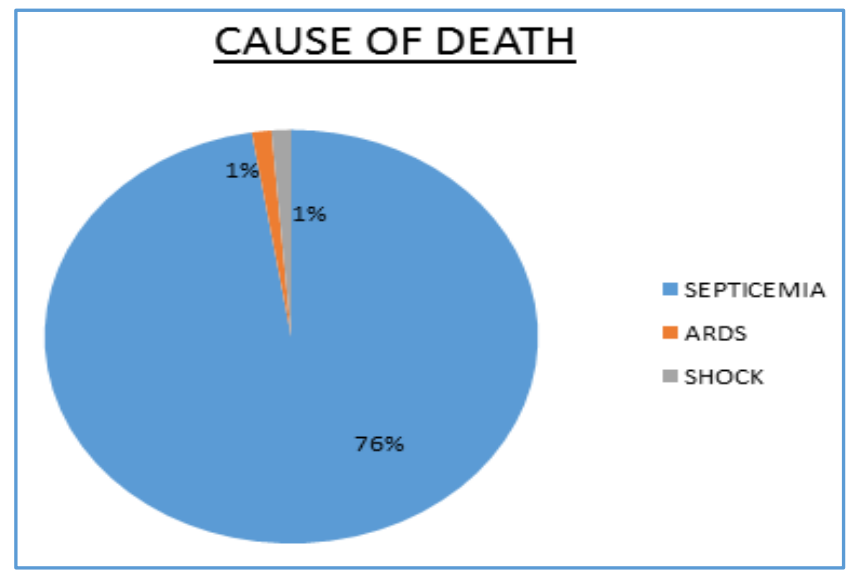

Sex wise Distribution

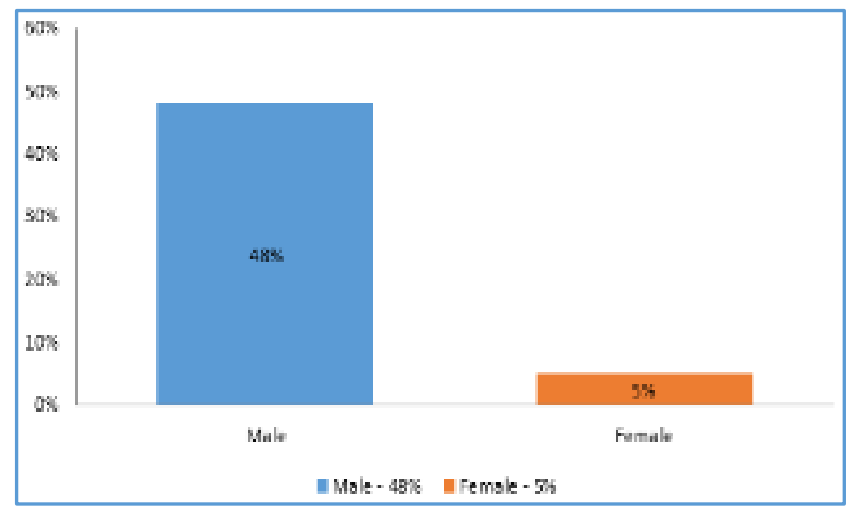

Organs Damaged in Blunt Trauma Abdomen

\section{Organ Damage}

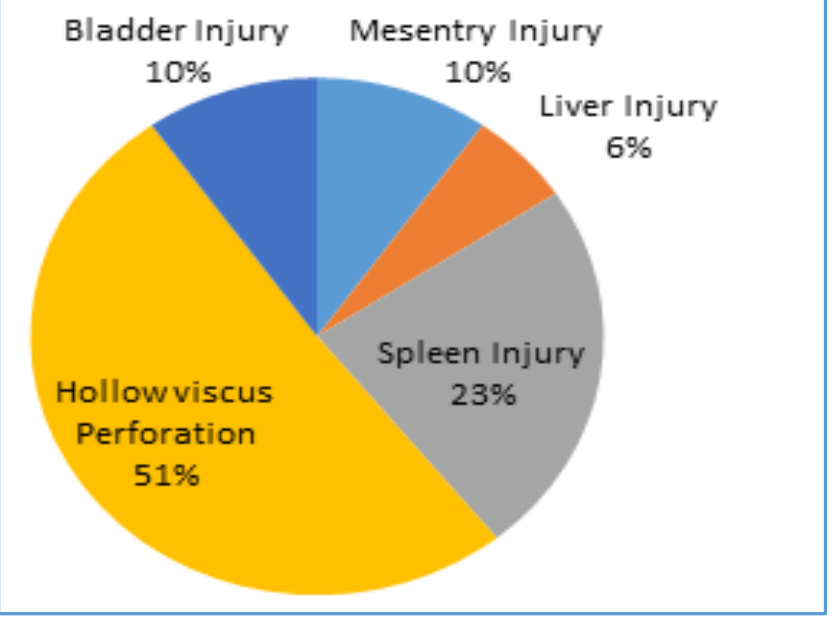

\section{CONCLUSION}

Road traffic accidents form the most common mode of injury. Measures should be taken to prevent these accidents and care the victims at the accident site. Thorough and repeated clinical examination and appropriate diagnostic investigation lead to successful treatment in these patients. Early exploration, rigorous measures of resuscitation, early diagnosis and decision of surgery, good trauma centres, good radiological and blood bank facilities, careful exploration and perfect technique for surgery and meticulous postoperative followup will all reduce in morality. In present study, we concluded that operative procedure yielded acceptable results mainly in unstable patients.

\section{REFERENCES}

1. Nishijima DK, Simel DL, Wisner DH, et al. Does this adult patient have blunt intra abdominal injury? JAMA 2012;307(14):1517-27.

2. Branney SW, Moore EE, Cantrill SV, et al. Ultrasound based key clinical pathway reduces the use of hospital resources for the evaluation of blunt abdominal trauma. J Trauma 1997;42:1086-1090.

3. Healey MA, Simons RK, Winchell RJ, et al. A prospective evaluation of abdominal ultrasound in blunt trauma: is it useful? J Trauma 1996;40:875-883.

4. Glaser K, Tschmelitsch J, Klingler P, et al. Ultrasonography in the management of blunt abdominal and thoracic trauma. Arch Surg 1994;129:743-747. 
5. Liu M, Lee $\mathrm{CH}$, P'eng FK. Prospective comparison of diagnostic peritoneal lavage, computed tomographic scanning, and ultrasonography for the diagnosis of blunt abdominal trauma. J Trauma 1993;35:267-270.

6. Boulanger BR, McLellan BA, Brenneman FD, et al. Emergent abdominal sonography as a screening test in a new diagnostic algorithm for blunt trauma. J Trauma 1996;40:867-874.

7. Ma OJ, Kefer MP, Mateer JR, et al. Evaluation of haemoperitoneum using a single-vs multiple-view ultrasonographic examination. Acad Emerg Med 1995;2:581-586.

8. Kawaguchi S, Toyonaga J, Ikeda K. Five point method: an ultrasonographic quantification formula of intraabdominal fluid collection. Jpn J Acute Med 1987;7:993-7.

9. Tiling T, Boulion B, Schmid A, et al. Ultrasound in blunt abdominothoracic trauma. In: Border JR, ed. Blunt multiple trauma: comprehensive pathophysiology and care. New York: Marcel Dekker, 1990;415-33.
10. Blaivas $M$, Brannam L, Hawkins $M$, et al. Bedside emergency ultrasonographic diagnosis of diaphragmatic rupture in blunt abdominal trauma. Am J Emerg Med 2004;22(7):601-4.

11. Lone GN, Peer GQ, Warn NA. An experience with abdominal trauma in adults in Kashmir. JK Pract 2001;8:225-30.

12. Modi N. Text book of Medical jurisprudence Tripathi NM. Pvt. Ltd. 1980;20 th edn:455-470.

13. Tonge, O’Reilly, Davison, et al. Traffic crash fatalities, injury pattern and other factor. medicine, science and law 1977;17:9-24.

14. Jolly S, Upadhyay M, Jam BL. Blunt abdominal trauma. A clinical study of 100 cases. Indian I Surg 1993;290-93. 